\title{
Jasada bhasma, a Zinc-Based Ayurvedic Preparation: Contemporary Evidence of Antidiabetic Activity Inspires Development of a Nanomedicine
}

\author{
Rinku D. Umrani and Kishore M. Paknikar \\ Centre for Nanobioscience, Agharkar Research Institute, G. G. Agarkar Road, Pune Maharashtra 411004, India \\ Correspondence should be addressed to Kishore M. Paknikar; kpaknikar@gmail.com
}

Received 31 July 2014; Revised 13 October 2014; Accepted 20 October 2014

Academic Editor: Cicero L. T. Chang

Copyright (C) 2015 R. D. Umrani and K. M. Paknikar. This is an open access article distributed under the Creative Commons Attribution License, which permits unrestricted use, distribution, and reproduction in any medium, provided the original work is properly cited.

\begin{abstract}
The roles of metals in human physiology are well established. It is also known that many metals are required in trace amounts for normal metabolism and their deficiency leads to diseases. In Ayurveda, metal-based preparations, that is, bhasmas, are indicated for the treatment of several diseases. Standard textbooks of Ayurveda recommend Jasada bhasma (zinc based bhasma) as the treatment of choice for diabetes. Modern medicine also recognizes the important role of zinc in glucose homeostasis. Yet, studies that validate the use of Jasada bhasma are few and uncomprehensive. There is an imminent need for a systematic study on physicochemical characterization, pharmacological efficacy, and toxicity assessment of several bhasma preparations to generate scientific evidence of their utility and safety. Interestingly, recent studies suggest that bhasmas comprise submicronic particles or nanoparticles. Thus a bhasma-inspired new drug discovery approach could emerge in which several metal based nanomedicines could be developed. This would help in utilizing the age old, time-tested wisdom of Ayurveda in modern medicine. One such study on antidiabetic activity of Jasada bhasma and the corresponding new drug, namely, zinc oxide nanoparticles, is briefly discussed, as an example.
\end{abstract}

\section{Diabetes}

Diabetes mellitus is a metabolic disorder manifested by the presence of hyperglycemia, that is, fasting glucose levels $>140 \mathrm{mg} / \mathrm{dL}$ and postprandial glucose levels $>200 \mathrm{mg} / \mathrm{dL}$. It is a heterogeneous group of disorders influenced by age, genetic composition, and environmental factors. The pancreatic $\beta$ cells and their secretory product, namely, insulin, are central in the pathophysiology of diabetes [1]. Based on the insulin levels and pancreatic function, two main types of diabetes are recognized. Insulin-dependent diabetes mellitus (IDDM) or type 1 diabetes is due to autoimmune destruction of the insulin-producing pancreatic $\beta$-cells resulting in an absolute deficiency of insulin. Therefore, type 1 diabetic patients need exogenous insulin for survival [2]. In noninsulin-dependent diabetes mellitus (NIDDM) or type 2 diabetes, muscle, liver, and fat cells become "resistant" to the actions of insulin. Also, the compensatory mechanisms that are activated in the $\beta$ cells to secrete more insulin are not sufficient to maintain blood glucose levels within a normal physiological range [1]. Besides type 1 and type 2 diabetes, several other forms of diabetes such as "maturity onset diabetes of the young" (MODY), "gestational diabetes," and "maternally inherited mitochondrial diabetes" (MIMD) are reported. However, the incidence of type 2 diabetes is the highest ( $90 \%)$ followed by type 1 diabetes ( $9 \%)$ among the diabetic population [2].

Currently, the only therapy for type 1 diabetes is administration of insulin and/or analogues (which differ from human insulin by one or two amino acids). Patient discomfort due to multiple injections a day and weight gain are major demerits. Considerable efforts have been made for the development of oral insulin for better patient compliance. However, such options are not yet available in the market and insulin remains the mainstay of treatment of type 1 diabetes.

Several oral antidiabetic agents are clinically used for the treatment of type 2 diabetes (Table 1). Life style and dietary changes are also recommended in early stage of the disease. Other than the listed agents, insulin and analogues are used 
TABLE 1: Summary of the current therapeutic agents for type 2 diabetes and associated side effects.

\begin{tabular}{|c|c|c|}
\hline Drug class/agent & Drug effect/action & Side effects/demerits \\
\hline Metformin & Suppresses hepatic glucose output & Lactic acidosis and GI problems \\
\hline Insulin secretagogues (sulphonylureas) & Increase insulin secretion & Hypoglycemia and weight gain \\
\hline PPAR $\gamma$ agonists (thiazolidinediones) & Increase insulin sensitivity & $\begin{array}{l}\text { Peripheral edema, weight gain, and } \\
\text { anemia }\end{array}$ \\
\hline Alpha-glucosidase inhibitors (acarbose) & Inhibit glucose absorption & Loose stools and flatulence \\
\hline GLP-1 analogues (liraglutide) & Increase glucose stimulated insulin secretion & $\begin{array}{l}\text { Patient compliance in case of peptide } \\
\text { analogues (injection) }\end{array}$ \\
\hline DPP-IV inhibitors (sitagliptin) & Enhance endogenous GLP-1 action & Specificity issues \\
\hline SGLT2 inhibitors (canagliflozin) & Inhibition of glucose reabsorption in kidneys & Urinary tract infections \\
\hline
\end{tabular}

in the late stage of type 2 diabetes, especially in patients with poor glycemic control. However, these therapies are associated with several side effects based on their mechanism of action [3-5], summarized in Table 1.

\section{Need for Newer Antidiabetic Drugs}

Most of the antidiabetic agents cannot be used as a single therapy and are used in combination with each other or with insulin, increasing the treatment cost. Despite available polytherapy, current unmet needs are

(i) enhanced insulin secretion without the risk of hypoglycemia,

(ii) increased insulin sensitivity without body weight gain,

(iii) improvement in dyslipidemia that coexists with diabetes,

(iv) preservation of pancreatic beta cell action and delayed beta cell failure,

(v) delayed development of diabetes related complications, namely, retinopathy, nephropathy, neuropathy, and cardiomyopathy.

A single, cost-effective, oral, antidiabetic treatment with minimal side effects is the need of the day. As an important part of the continued research on developing newer antidiabetic agents, several metals are being investigated for beneficial effects in both type 1 and type 2 diabetes and associated complications. These include vanadium, chromium, magnesium, selenium, cobalt, zinc, tungsten, and molybdenum. Of these metals, zinc is of particular interest due to its pleiotropic role as discussed below.

\section{Role of Zinc in Glucose Metabolism}

Zinc is an essential micronutrient, found in all tissues of the body, 95\% of it being intracellular [6]. Being a cofactor of more than 300 enzymes, zinc is involved in all cellular functions including signal transduction, transcription, and replication [7]. Zinc is also a cofactor in DNA, RNA, and protein synthesis and influences gene expression through transcription factors [8]. Zinc also plays a role in growth,

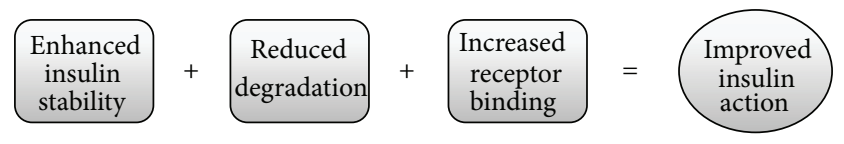

FIGURE 1: A schematic of the reported mechanisms by which zinc improves insulin action [9-13].

development, apoptosis, immune function, reproduction, maintenance of vision, protein digestion, blood clotting, bone metabolism, and carbohydrate metabolism.

The pancreas is the site of insulin synthesis, storage, and secretion, and zinc is involved in each of these processes [9]. Even before any evidence of a relationship between zinc and insulin existed, it was known that addition of zinc extended insulin's duration of action [10]. As early as 1930 's, zinc was known to be important for the integrity of the crystalline structure of insulin [11]. In the presence of zinc within the beta cell, insulin monomers assemble to a dimeric form for storage and secretion as the zinc crystal. Dimeric insulin assembles further into a hexamer that is relatively more stable form of insulin [12]. Zinc not only prevents the degradation of insulin hexamers but also improves the binding of insulin to its receptors and inhibits degradation by liver plasma membranes [13]. These reported mechanisms might be working together to improve insulin action (Figure 1).

Insulin mimetic actions of zinc are also known, reported as early as 1980, where zinc chloride stimulated lipogenesis in rat adipocytes [14]. It is now known that these insulin mimetic effects in adipocytes are through a complex interplay of improved insulin signaling, increased glucose transport, phosphodiesterase activation, and inhibition of free fatty acids release [15]. Haase and Maret [16] reported PTP1B inhibition by zinc, thus enhancing insulin signaling. Further, zinc enhances insulin signaling by increased insulin receptor tyrosine phosphorylation, enhanced PI3K activity, and inhibition of GSK3 [17].

Zinc also has beneficial effects on glucose metabolism. Inhibition of intestinal glucose absorption by zinc has been reported [18]. By inhibiting fructose 1,6-bisphosphatase [13], zinc favors glycolysis as opposed to gluconeogenesis in the cell. Zinc induces the translocation of glucose transporters (GLUT4) to plasma membrane in adipocytes [19, 20], thus increasing glucose uptake and reducing blood glucose levels. 


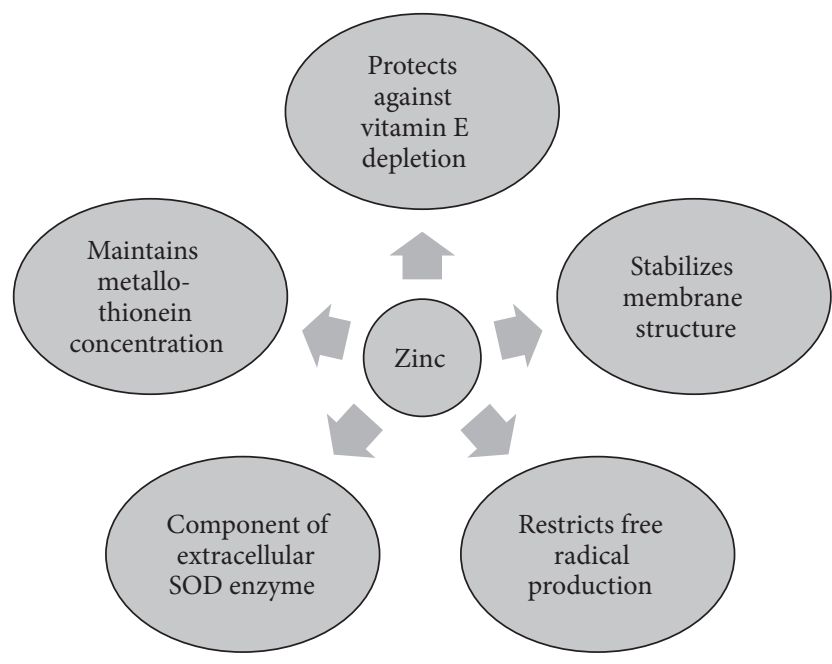

FIGURE 2: A schematic of the several antioxidant actions of zinc.

In the adipocytes, insulin regulates the activity of hormone sensitive lipase (HSL) and thereby inhibits lipolysis. This favors lipogenesis and storage of fat. It is known that, in diabetes, insulin's regulation over lipolysis is lost. This results in increased free fatty acids in blood. It is also known that these elevated FFAs impair beta cell function through ceramide production and induce apoptosis. The resulting pancreatic beta cell decompensation worsens the diabetic situation. Interestingly, zinc suppresses phosphorylation of hormone sensitive lipase (HSL), thereby inhibiting free fatty acids release [21]. Zinc deficiency may modify lipid metabolism and membrane integrity and these could impair glucose carrier function [13]. Inhibition of GSK3 by zinc [14] exerts beneficial effects on glycogen metabolism. Also, zinc is reported to inhibit glucagon secretion [22, 23], thus reducing gluconeogenesis and glycogenolysis.

Zinc ions also have pronounced effects on redox metabolism, although they are redox inert. Depending on how much zinc is readily available, zinc can either increase the cell's antioxidant capacity or elicit oxidative stress [24]. Zinc contributes to antioxidant defense as a component of $\mathrm{Cu}-\mathrm{Zn}$ superoxide dismutase and metallothionein. Several mechanisms contribute to the antioxidant effects of zinc [25], summarized in Figure 2.

Zinc also protects beta cells from death, thereby ensuring higher plasma insulin levels. This is achieved by reduced production of interleukins and TNF- $\alpha$, inflammatory mediators of cell death [17]. Ho et al. [26] reported that zinc protected beta cells from oxidative damage and death in streptozotocin and alloxan induced diabetic models.

Thus, zinc plays a pleiotropic role in the maintenance of glucose homeostasis. These metabolic actions of zinc and their mechanism are summarized in Table 2.

Interestingly, it is also known that zinc deficiency coexists with diabetes [12]. Patients with diabetes are more likely to have suboptimal zinc status and a negative correlation has been observed between zinc intake and prevalence of diabetes [27]. Whether zinc deficiency is cause or effect of hyperglycemia is still debatable. Diabetes itself affects zinc homeostasis in many ways resulting in decreases in total body zinc [12]. Zinc deficiency is associated with impairment in glucose tolerance and also an increased sensitivity to diabetogenic agents [26]. Zinc deficiency may also affect the progress of type 2 diabetes. Reduced zinc may also exacerbate the oxidative stress mediated complications of diabetes.

Several preclinical studies have demonstrated the antihyperglycemic effects of zinc supplementation in animal models of type 1 as well as type 2 diabetes [27-29]. Thus, it can be reasoned that a zinc based agent can be used for diabetes therapy. Orally active antidiabetic zinc complexes have also been developed [15, 18, 21, 30,31]. Despite well proven results in animal models, these zinc complexes are not yet available as antidiabetic therapies in modern medicine.

\section{Zinc Based Drug in Ayurveda: Jasada bhasma}

Ayurveda is an ancient Indian system of medicine dating back to 5000 B.C. Ayurveda uses plant-, animal-, mineral-, and metal-based medicines for the treatment of diseases [3234]. "Rasashastra," an integral part of Ayurveda, deals with drugs of mineral origin and details their varieties, characteristics, processing techniques, properties, therapeutic uses, and management of adverse effects in a comprehensive way [35]. It was known in Ayurveda that metals as compared to animal and plant products were not compatible with human body constitution. They could not be consumed in their natural form, hence needed to be processed into fine and soft powder termed "bhasma" [36]. The preparation of bhasmas includes two main stages: shodhan (purification) and maaran (incineration). Shodhan process involves repeated trituration with herbal extracts, cow urine, milk, ghee, and so forth. Maaran process involves repeated cycles of incineration. Thus, bhasmas are metals that go through a purification and incineration process that turns them into ash $[37,38]$.

It was known that incomplete processing would result in metal ion impurities leading to adverse effects and toxicity. Therefore, tests were developed to evaluate the particle size, density, and physical and chemical stability of bhasmas. Compliance to these tests indicated complete conversion of metal to oxide form and desired size reduction, thereby implicating safety of the bhasma [39]. However, these tests are only qualitative and do not provide information about the chemical composition of bhasmas [40]. Pharmaceutical characterization is therefore necessary to identify all the active ingredients in bhasmas [41], since most of them are complex herbomineral preparations. Further, standardization of the raw materials, the synthesis procedure, and the finished product is also needed, which ultimately affects the purity, quality, and safety of the bhasma [42]. Several modern tools and techniques (namely, electron microscopy, $\mathrm{X}$-ray diffraction, and atomic absorption spectrometry) can be employed to obtain detailed information on the size, structure, and elemental composition of bhasmas.

A condition similar to diabetes is recognized in Ayurveda, termed "Madhumeha" which means honey-like urine [43, 44]. Ayurvedic treatment of diabetes includes several herbal 
TABLE 2: A summary of metabolic actions of zinc and their mechanism.

\begin{tabular}{|c|c|c|}
\hline Metabolic action & Mechanism of action & References \\
\hline Increases insulin action & Increases stability and receptor binding & {$[11,12]$} \\
\hline Improves insulin signaling & PTP1B inhibition & {$[16]$} \\
\hline Enhances insulin signaling & Increases receptor phosphorylation and PI3K activity & [17] \\
\hline Beneficial effect on glycogen metabolism & GSK3 inhibition & {$[14]$} \\
\hline Increases glucose uptake & GLUT4 translocation in adipocytes & {$[19,20]$} \\
\hline Decreases lipolysis & Inhibition of HSL and FFA release & [21] \\
\hline Inhibits glucagon secretion & Opening of $\mathrm{K}_{\mathrm{ATP}}$ channels in pancreatic alpha cells & {$[22,23]$} \\
\hline Inhibits intestinal glucose absorption & Inhibits alpha-glucosidase enzyme & {$[18]$} \\
\hline Reduces oxidative stress & Enhances SOD activity & {$[25]$} \\
\hline Protects beta cells & Modulates NF $\kappa$ B activation & {$[26]$} \\
\hline
\end{tabular}

drugs and also a few mineral preparations including bhasmas [45]. In the texts of Rasashastra [46], bhasmas of Mandura (iron), Vanga (tin), Naga (lead), Tamra (copper), and Jasada (zinc) have been recommended for the treatment of diabetes. A few scientific reports on the clinical use of bhasmas in diabetic patients are available $[47,48]$.

Jasada bhasma (also known as Yashada bhasma) is also indicated in various disorders, namely, diabetes, anemia, cough, ulcers, depression, ophthalmic problems, and so forth [49-52]. Standard textbooks on Rasashastra recommend Jasada bhasma as the treatment of choice for diabetes. However, studies related to pharmacological/clinical investigation of Jasada bhasma as antidiabetic agent are few and not comprehensive [53-55]. Clearly, there is a need for undertaking a detailed and systematic study on the proclaimed antidiabetic efficacy of Jasada bhasma.

Recent renewed interest in Ayurveda has led to scientific investigations on therapeutic utility of several bhasmas [5662]. Apart from pharmacological validation, pharmaceutical characterization of these bhasmas is also necessary. Interestingly, detailed investigation on the composition of bhasmas is being carried out by researchers, using modern analytical techniques. Recent reports have suggested the presence of submicronic particles or nanoparticles in bhasma preparations. Gold nanoparticles have been detected in Swarna bhasma and the formulation is effective antiarthritic agent in rats [63]. Bhowmick et al. [64] reported zinc oxide particles of size $\sim 1$ micron in traditionally prepared Jasada bhasma. Physicochemical characterization of Naga (lead) bhasma revealed micron sized particles of lead oxide [65]. Similarly, studies on Swarna makshika bhasma revealed that raw Swarna makshika is a complex compound that gets converted to simple oxides [66], with micron sized particles [67].

Reports are also available that provide scientific evidence of the incineration cycles during synthesis of bhasmas. For example, Wadekar et al. [38] evaluated tin based bhasma sample at various stages of calcination and found that the proportion of tin oxide increased with the number of calcination cycles while the particles size stabilized at $\sim 1$ micron after the final calcination cycle. Singh and Reddy [68] detected 300 to $500 \mathrm{~nm}$ sized particles in Lauha bhasma. Further, they observed successive decrease in particle size of
Lauha bhasma with increase in the number of incineration cycles. In another study using Lauha bhasma, it was found that the incineration steps were critical for the formation of nanostructures [69]. Thus, it may be suggested that bhasmas contain submicronic particles or nanoparticles of the metal oxide if prepared extremely well.

It is well known that size reduction of particles increases solubility and hence bioavailability. Therefore bhasmikaran is expected to reduce the size of metal oxide particles enhancing their bioavailability and bioactivity. Interestingly, in modern science, several researchers have demonstrated enhanced bioavailability of nanoparticles as compared to their bulk form. For example, Ishihara et al. [70] reported higher bioavailability of micronized zinc oxide as compared to standard zinc oxide. In another report, poor water soluble iron compounds when formulated as nanoparticles displayed oral bioavailability similar to soluble salts [71]. Thus, it is safe to assume that bhasmas contain nanoparticles that lead to enhanced bioactivity.

\section{Scientific Studies on Jasada bhasma and Its Use in Diabetes Treatment}

Over this background of concordance of modern science and Ayurveda, as a case in point, we undertook a systematic study on the physicochemical characterization, antidiabetic efficacy, and safety assessment of Jasada bhasma (zinc bhasma). In an elaborate study conducted in our laboratory, Jasada bhasma was synthesized using traditional method and evaluated for its composition, size, shape, and morphology using several modern physicochemical techniques, namely, high resolution transmission electron microscopy (HRTEM) coupled with selective area electron diffraction (SAED), scanning electron microscopy (SEM) coupled with energy dispersive X-ray spectroscopy (EDS), X-ray diffraction (XRD), and atomic absorption spectrometry (AAS). Efficacy was evaluated using standard pharmacological methods in diabetic rats. Bioavailability and toxicity of Jasada bhasma were also assessed in rats.

SEM and HRTEM showed that the traditionally prepared Jasada bhasma consisted of 200-500 nm sized particles (Figure 3). EDS, SAED, AAS, and XRD analysis revealed that 


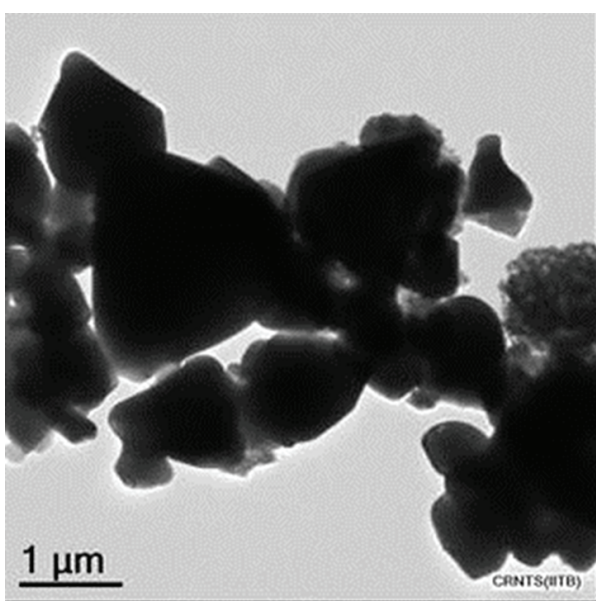

(a)

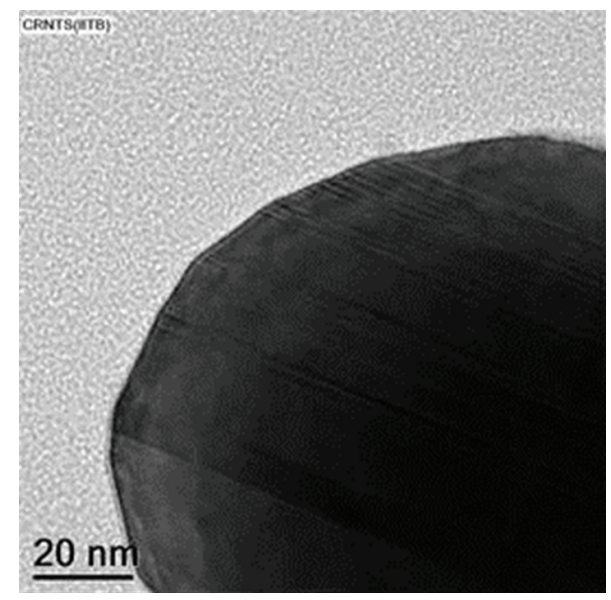

(b)

Figure 3: Presence of submicronic particles in Jasada bhasma. Images were taken by transmission electron microscopy at low (a) and high (b) magnification.

the preparation consisted predominantly of zinc oxide with hexagonal wurtzite crystal structure (details mentioned in [72]).

Dose range finding studies were carried out in normoglycemic Wistar rats. The dose used in Ayurveda (125 mg, twice a day) led us to simple calculation of $250 \mathrm{mg}$ per day divided by average human body weight of $70 \mathrm{~kg}$, for example, $3.5 \mathrm{mg} / \mathrm{kg}$. To evaluate dose dependent effects, the doses of $3 \mathrm{mg} / \mathrm{kg}$ and above were selected. The effective dose range of Jasada bhasma in oral glucose tolerance tests was found to be $3-30 \mathrm{mg} / \mathrm{kg}$. For efficacy evaluation, Jasada bhasma (1, 3, $10 \mathrm{mg} / \mathrm{kg}$ ) was administered orally, once daily for 4 weeks, to streptozotocin (STZ) induced type 1 and type 2 diabetic rats. For induction of type 1 diabetes, adult rats were administered $45 \mathrm{mg} / \mathrm{kg}$ STZ intravenously whereas, for type 2 diabetes, 5day-old pups were injected STZ intraperitoneally at the dose of $90 \mathrm{mg} / \mathrm{kg}$.

In case of type 1 diabetic rats, Jasada bhasma treatment showed reduction of nonfasted ( $20 \%$ at $10 \mathrm{mg} / \mathrm{kg}$ dose $)$ as well as fasted blood glucose levels ( $\sim 33 \%$ at $10 \mathrm{mg} / \mathrm{kg}$ dose). These results were comparable to glibenclamide, used as a positive control. In OGTT, Jasada bhasma showed a trend of suppressed glucose levels as well as reduced AUC values $(\sim 16 \%)$. Treatment also decreased the nonfasted serum insulin levels $(\sim 32 \%$ at $10 \mathrm{mg} / \mathrm{kg}$ dose $)$, suggesting insulin sensitizing effects. In case of type 2 diabetic rats, treatment with Jasada bhasma resulted in improved glucose tolerance $(\sim 19 \%)$, lowered nonfasted ( $20 \%)$ as well as fasted blood glucose levels ( $\sim 27 \%)$, and reduced serum insulin levels $(\sim 27 \%)$. These effects were found to be comparable to pioglitazone, a drug widely used clinically.

Next, we evaluated the solubility of Jasada bhasma using a simple dialysis experiment. Several researchers have used this technique to estimate nanoparticle dissolution and predict bioavailability. It was found that the dialysability was around $30 \%$ in gastric $\mathrm{pH}$, suggesting release of zinc ions. Systemic absorption was assessed by single dose pharmacokinetic study where serum zinc levels were found to be elevated (3.5 folds) after oral administration of Jasada bhasma [72].
Since there are lots of concerns related to the toxicity of metallic medicines, we also employed a comprehensive testing strategy for assessment of toxicity profile of Jasada bhasma. Cytotoxicity test revealed no loss of cell viability and no effects on cell morphology. Hemolysis was less than $5 \%$ (within acceptable limits) after oral administration of Jasada bhasma to rats. Acute and subacute toxicity tests demonstrated safety of Jasada bhasma up to $300 \mathrm{mg} / \mathrm{kg}$ dose in rats [73]. These findings provide concrete scientific evidence that justifies usage of Jasada bhasma in diabetes treatment.

\section{Relevance of Jasada bhasma to Zinc Oxide Nanoparticles Based Drug}

Encouraged by the results obtained in case of Jasada bhasma, we extended our work towards the development of a zinc based antidiabetic agent for modern medicine. Since our studies clearly demonstrated the presence of submicronic zinc oxide particles in Jasada bhasma, we hypothesized that nanoparticles of zinc oxide $(\leq 10 \mathrm{~nm}$ size) should also be able to exert antidiabetic effects. An elaborate study was undertaken to investigate this possibility $[74,75]$.

In proof of concept studies, single administration of zinc oxide nanoparticles resulted in significant suppression of glucose levels in OGTT carried out in both type 1 and type 2 diabetic rats $(\sim 22 \%$ and $\sim 30 \%$, resp.). These effects appeared to be more prominent than those obtained with similar doses of Jasada bhasma. After 4 weeks of treatment (1, 3 , and $10 \mathrm{mg} / \mathrm{kg}$ doses) to diabetic rats, significant reduction in glucose levels was seen in both nonfasted $(\sim 19 \%$ and $\sim 29 \%$ in type 1 and type 2 diabetic rats, resp.) and fasted state $(\sim 26 \%$ and $\sim 21 \%$ in type 1 and type 2 diabetic rats, resp.), suggesting multiple mechanisms. Reduction of nonfasted glucose levels can be attributed to insulin secretagogue effects. Reduction of fasted glucose levels may be due to glucagon inhibition, as is reported with zinc $[22,23]$. Increased serum insulin levels ( $\sim 35 \%$ and $\sim 70 \%$ in type 1 and type 2 diabetic rats, resp.) 
suggested insulin secretagogue effects. Reduction in serum TG ( 48\%) and FFA ( 41\%) levels was also observed after treatment indicating beneficial effects on lipid metabolism. Overall results suggested that zinc oxide nanoparticles were more potent and efficacious than Jasada bhasma [74].

Differences in efficacy of Jasada bhasma (200-500 nm particles) and zinc oxide nanoparticles $(\leq 10 \mathrm{~nm})$ suggested possible size dependent differences in bioavailability. Dialysability experiments revealed better dissolution and release of zinc ions from zinc oxide nanoparticles $(\sim 40 \%)$ as compared to Jasada bhasma ( 30\%). Further, it was found that $>50 \%$ of the total zinc was left undialyzed. These results suggested that under in vivo conditions, Jasada bhasma, and zinc oxide nanoparticles are encountered as zinc ions as well as particulates, after oral administration [74].

The soluble fraction of Jasada bhasma and zinc oxide nanoparticles could get immediately absorbed from the intestine and result in initial spurt of zinc in blood. The particulates could be taken up by enterocytes through size limited endocytosis. It could be expected that the uptake of particulate fraction of zinc oxide nanoparticles from the intestine would be higher than that of Jasada bhasma. In circulation, very small particles (1-20 nm) can slowly extravasate into the interstitial spaces and then can be taken up by tissue cells [76]. Once in cells, particles encounter increasing acidic environment as they move from early to late endosomes and finally to lysosomes, resulting in dissolution of particulates [77]. Particulate component would thus result in slow and continuous release of zinc ions, acting as a depot.

As predicted, pharmacokinetic evaluation showed that serum and tissue zinc levels in zinc oxide nanoparticles treated rats were higher than Jasada bhasma treated rats. Further, serum zinc levels were maintained for $24 \mathrm{~h}$ in zinc oxide nanoparticles treated rats, whereas they declined within $4 \mathrm{~h}$ in Jasada bhasma treated rats. Long circulation of zinc oxide nanoparticles as compared to Jasada bhasma could possibly increase chances of their passage to tissues and hence higher cellular uptake, corresponding to the observed higher tissue zinc levels. These results correlated with in vivo efficacy studies where zinc oxide nanoparticles displayed a more potent and efficacious antidiabetic profile than Jasada bhasma [74].

Next, Jasada bhasma and zinc oxide nanoparticles were investigated in rat insulinoma (RIN5f) cell line to elucidate the possible mechanism of antidiabetic activity. Jasada bhasma did not enhance insulin secretion, whereas zinc oxide nanoparticles resulted in dose- and glucose- dependent insulin secretagogue effects. These results suggested that Jasada bhasma had poor cell permeability. Further, zinc oxide nanoparticles treatment per se enhanced SOD activity of RIN5f cells and also protected cells against $\mathrm{H}_{2} \mathrm{O}_{2}$ induced oxidative stress, suggesting antioxidant effects. Since uncontrolled hyperglycemia and oxidative stress contribute to development of diabetic complications, zinc oxide nanoparticles by virtue of antihyperglycemic and antioxidant effects may be expected to delay the progression of disease and development of associated complications [74].

Several toxicity tests were then performed to evaluate the safety of zinc oxide nanoparticles. Cytotoxicity was not seen up to $10 \mu \mathrm{g} / \mathrm{mL}$ concentrations of zinc oxide nanoparticles (concentrations resulting in insulin secretion) in RIN5f cells. Further to evaluate genotoxic effects of zinc oxide nanoparticles, in vivo micronucleus test was performed using Wistar rats. Micronuclei formation was not increased after zinc oxide nanoparticles treatment, indicating no risk of genotoxicity [75].

Since significant antihyperglycemic activity was seen at $3 \mathrm{mg} / \mathrm{kg}$ dose, toxicity studies were performed at 30 and $300 \mathrm{mg} / \mathrm{kg}$, for example, 10 and 100 times the effective dose. In acute toxicity study, no behavioral abnormality or clinical signs or mortality was recorded after zinc oxide nanoparticles treatment at $300 \mathrm{mg} / \mathrm{kg}$ dose. Further, no effect was seen on body weight and major organ weights and tissue histology. In subacute toxicity test, 28 days of treatment with zinc oxide nanoparticles at two doses, 30 and $300 \mathrm{mg} / \mathrm{kg}$, did not result in any significant effects on body weight gain or organ weight to body weight ratios. SGOT and SGPT activities and creatinine and urea levels were not altered in treatment groups as compared to control group, indicating no major organ damage. Histological examination of tissue sections did not reveal any necrotic damage. Taken together, toxicity studies revealed the safety of zinc oxide nanoparticles up to 100 times the effective dose [75].

Overall, it was clearly evident from our studies that zinc oxide nanoparticles can elicit potent antidiabetic activity in type 1 and type 2 diabetic rats [75]. Thus, taking inspiration from the usage of Jasada bhasma in diabetes, a new chemical entity (zinc oxide nanoparticles) is proposed in modern medicine warranting further investigation.

\section{Conclusions and Future Prospects}

The roles of metals in human physiology are well established. It is also known that many metals are required in trace amounts for normal metabolism and their deficiency leads to diseases. In Ayurveda, metal-based preparations, for example, bhasmas, are indicated for the treatment of several diseases. However, in present day Ayurvedic practice, the use of bhasmas is limited. This could be because the synthesis procedures of bhasmas are laborious, time consuming, and often difficult to interpret from ancient texts. Different protocols exist to get several types of bhasma of the same metal. Hence, selection of the synthesis protocol requires sound knowledge of the Ayurveda system. To address this issue, standardization of the synthesis procedure and its detailed documentation would be helpful.

Standards for manufacture and quality control are not yet properly defined and enforced. Development of detailed testing strategy using modern analytical tools would be useful for ensuring quality of bhasmas, especially absence of heavy metal impurities. FDA regulations for sale of bhasmas need to be clearly defined and executed to avoid the use of substandard drugs.

Parallely, scientific studies on all the bhasmas described in Ayurvedic texts are needed. Pharmacological validation studies can be undertaken to generate evidence of the efficacy of bhasmas. Further, detailed investigation of 
the mechanism of action using modern research tools (namely, proteomics and genomics) will help solve the mystery of the observed effects of these Ayurvedic medicines. For example, a report on Rasa-Sindoor (mercury and sulfur) has detailed the various mechanisms by which it exerts a holistic effect in neurodegenerative disorders such as Huntington's and Alzheimer's disease [78]. Moreover, Ayurvedic practitioners should be encouraged to publish reports of patient outcomes. Such reports will add the much needed clinical evidence of the utility of bhasmas.

Most importantly, the knowledge gained out of Ayurvedic texts and evidence based studies should be extended to modern medicine. Although there are several drugs available for diabetes in the market, none of them is free from adverse effects. On the other hand, Ayurvedic medicines, namely, bhasmas, are known to be effective at very low doses and devoid of toxic effects. Once the active ingredients of bhasmas are identified, these metal oxides can be synthesized and evaluated as a new chemical entity in modern drug discovery. Taking inspiration from the fact that bhasmas contain submicronic or nanoparticles that enhance bioavailability, metal based nanomedicines can be developed for diabetes. This would help in utilizing the age old wisdom of Ayurveda for the development of newer drugs in modern medicine.

\section{Conflict of Interests}

The authors declare that there is no conflict of interests regarding the publication of this paper.

\section{Acknowledgments}

Rinku D. Umrani thanks the Indian Council of Medical Research for the award of Senior Research Fellowship.

\section{References}

[1] G. I. Bell and K. S. Polonsky, "Diabetes mellitus and genetically programmed defects in $\beta$-cell function," Nature, vol. 414, no. 6865, pp. 788-791, 2001.

[2] P. Zimmet, K. G. M. M. Alberti, and J. Shaw, "Global and societal implications of the diabetes epidemic," Nature, vol. 414, no. 6865, pp. 782-787, 2001.

[3] N. Morral, "Novel targets and therapeutic strategies for type 2 diabetes," Trends in Endocrinology and Metabolism, vol. 14, no. 4, pp. 169-175, 2003.

[4] D. E. Moller, "New drug targets for type 2 diabetes and the metabolic syndrome," Nature, vol. 414, no. 6865, pp. 821-827, 2001.

[5] A. Philis-Tsimikas, "Type 2 diabetes: limitations of current therapies," Consultant, vol. 7, pp. S5-S11, 2009.

[6] P. Mason, "Physiological and medicinal zinc," Pharmaceutical Journal, vol. 276, no. 7390, pp. 271-274, 2006.

[7] L. Rink and H. Kirchner, "Zinc-altered immune function and cytokine production," Journal of Nutrition, vol. 130, no. 5, pp. 1407S-1411S, 2000.

[8] R. S. MacDonald, "The role of zinc in growth and cell proliferation," Journal of Nutrition, vol. 130, no. 5, pp. 1500S-1508S, 2000 .
[9] C. G. Taylor, "Zinc, the pancreas, and diabetes: insights from rodent studies and future directions," BioMetals, vol. 18, no. 4, pp. 305-312, 2005.

[10] J. A. Meyer and D. M. Spence, "A perspective on the role of metals in diabetes: past findings and possible future directions," Metallomics, vol. 1, no. 1, pp. 32-41, 2009.

[11] Q. Sun, R. M. Van Dam, W. C. Willett, and F. B. Hu, "Prospective study of zinc intake and risk of type 2 diabetes in women," Diabetes Care, vol. 32, no. 4, pp. 629-634, 2009.

[12] A. B. Chausmer, "Zinc, insulin, and diabetes," Journal of the American College of Nutrition, vol. 17, no. 2, pp. 109-115, 1998.

[13] M. J. Salgueiro, N. Krebs, M. B. Zubillaga et al., "Zinc and diabetes mellitus: is there a need of zinc supplementationin diabetes mellitus patients?" Biological Trace Element Research, vol. 81, no. 3, pp. 215-228, 2001.

[14] H. Sakurai and Y. Adachi, "The pharmacology of the insulinomimetic effect of zinc complexes," BioMetals, vol. 18, no. 4, pp. 319-323, 2005.

[15] H. Sakurai, A. Katoh, and Y. Yoshikawa, "Chemistry and biochemistry of insulin-mimetic vanadium and zinc complexes: trial for treatment of diabetes mellitus," Bulletin of the Chemical Society of Japan, vol. 79, no. 11, pp. 1645-1664, 2006.

[16] H. Haase and W. Maret, "Fluctuations of cellular, available zinc modulate insulin signaling via inhibition of protein tyrosine phosphatases," Journal of Trace Elements in Medicine and Biology, vol. 19, no. 1, pp. 37-42, 2005.

[17] J. Jansen, W. Karges, and L. Rink, "Zinc and diabetes—clinical links and molecular mechanisms," Journal of Nutritional Biochemistry, vol. 20, no. 6, pp. 399-417, 2009.

[18] E. Ueda, Y. Yoshikawa, H. Sakurai, Y. Kojima, and N. M. Kajiwara, "In vitro alpha-glucosidase inhibitory effect of $\mathrm{Zn}$ (II) complex with 6-methyl-2-picolinmethylamide," Chemical \& Pharmaceutical Bulletin, vol. 53, no. 4, pp. 451-452, 2005.

[19] O. Ezaki, "IIb group metal ions $\left(\mathrm{Zn}^{2+}, \mathrm{Cd}^{2+}, \mathrm{Hg}^{2+}\right)$ stimulate glucose transport activity by post-insulin receptor kinase mechanism in rat adipocytes," The Journal of Biological Chemistry, vol. 264, no. 27, pp. 16118-16122, 1989.

[20] X. H. Tang and N. F. Shay, "Zinc has an insulin-like effect on glucose transport mediated by phosphoinositol-3-kinase and Akt in 3T3-L1 fibroblasts and adipocytes," Journal of Nutrition, vol. 131, no. 5, pp. 1414-1420, 2001.

[21] A. Nakayama, M. Hiromura, Y. Adachi, and H. Sakurai, "Molecular mechanism of antidiabetic zinc-allixin complexes: regulations of glucose utilization and lipid metabolism," Journal of Biological Inorganic Chemistry, vol. 13, no. 5, pp. 675-684, 2008.

[22] I. Franklin, J. Gromada, A. Gjinovci, S. Theander, and C. B. Wollheim, " $\beta$-cell secretory products activate $\alpha$-cell ATPdependent potassium channels to inhibit glucagon release," Diabetes, vol. 54, no. 6, pp. 1808-1815, 2005.

[23] L. Egefjord, A. B. Petersen, A. M. Bak, and J. Rungby, "Zinc, alpha cells and glucagon secretion," Current Diabetes Reviews, vol. 6, no. 1, pp. 52-57, 2010.

[24] W. Maret, "Zinc and diabetes," BioMetals, vol. 18, no. 4, pp. $293-$ 294, 2005.

[25] R. A. DiSilvestro, "Zinc in relation to diabetes and oxidative disease," Journal of Nutrition, vol. 130, no. 5, pp. 1509S-1511S, 2000.

[26] E. Ho, C. Courtemanche, and B. N. Ames, "Zinc deficiency induces oxidative DNA damage and increases P53 expression in human lung fibroblasts," Journal of Nutrition, vol. 133, no. 8 , pp. 2543-2548, 2003. 
[27] J. U. Ukperoro, N. Offiah, T. Idris, and D. Awogoke, "Antioxidant effect of zinc, selenium and their combination on the liver and kidney of alloxan-induced diabetes in rats," Mediterranean Journal of Nutrition and Metabolism, vol. 3, no. 1, pp. 25-30, 2010.

[28] S. F. Simon and C. G. Taylor, "Dietary zinc supplementation attenuates hyperglycemia in $d b / d b$ mice," Experimental Biology and Medicine, vol. 226, no. 1, pp. 43-51, 2001.

[29] M.-D. Chen, S.-J. Liou, P. I.-Y. Lin, V. C. Yang, P. S. Alexander, and W.-H. Lin, "Effects of zinc supplementation on the plasma glucose level and insulin activity in genetically obese (ob/ob) mice," Biological Trace Element Research, vol. 61, no. 3, pp. 303311, 1998.

[30] Y. Kojima, Y. Yoshikawa, E. Ueda et al., "Insulinomimetic zinc(II) complexes with natural products: In vitro evaluation and blood glucose lowering effect in KK-Ay mice with type 2 diabetes mellitus," Chemical and Pharmaceutical Bulletin, vol. 51, no. 8, pp. 1006-1008, 2003.

[31] Y. Yoshikawa, Y. Adachi, and H. Sakurai, "A new type of orally active anti-diabetic $\mathrm{Zn}(\mathrm{II})$-dithiocarbamate complex," Life Sciences, vol. 80, no. 8, pp. 759-766, 2007.

[32] M. Barve, M. Mashru, C. Jagtap, B. J. Patgiri, and P. K. Prajapati, "Therapeutic potentials of metals in ancient India: a review through Charaka Samhita," Journal of Ayurveda and Integrative Medicine, vol. 2, no. 2, pp. 55-63, 2011.

[33] S. Dev, "Ancient-modern concordance in ayurvedic plants: some examples," Environmental Health Perspectives, vol. 107, no. 10, pp. 783-789, 1999.

[34] B. Patwardhan and R. A. Mashelkar, "Traditional medicineinspired approaches to drug discovery: can Ayurveda show the way forward?" Drug Discovery Today, vol. 14, no. 15-16, pp. 804811, 2009.

[35] P. K. Sarkar, S. Das, and P. K. Prajapati, "Ancient concept of metal pharmacology based on Ayurvedic literature," Ancient Science of Life, vol. 29, no. 4, pp. 1-6, 2010.

[36] S. Savrikar and B. Ravishankar, "Introduction to "Rasashaastra" the Iatrochemistry of Ayurveda," African Journal of Traditional, Complementary and Alternative Medicines, vol. 8, no. 5, pp. 6682, 2011 .

[37] R. Devanathan, "Concept of bhasmikarana," International Journal of Research in Ayurveda and Pharmacy, vol. 2, no. 1, pp. 1823, 2011.

[38] M. P. Wadekar, C. V. Rode, Y. N. Bendale, K. R. Patil, A. B. Gaikwad, and A. A. Prabhune, "Effect of calcination cycles on the preparation of tin oxide based traditional drug: studies on its formation and characterization," Journal of Pharmaceutical and Biomedical Analysis, vol. 41, no. 4, pp. 1473-1478, 2006.

[39] M. P. Wadekar, C. V. Rode, Y. N. Bendale, K. R. Patil, and A. A. Prabhune, "Preparation and characterization of a copper based Indian traditional drug: Tamra bhasma," Journal of Pharmaceutical and Biomedical Analysis, vol. 39, no. 5, pp. 951955, 2005.

[40] S. K. Singh, D. N. S. Gautam, M. Kumar, and S. B. Rai, "Synthesis, characterization and histopathological study of a leadbased Indian traditional drug: Naga Bhasma," Indian Journal of Pharmaceutical Sciences, vol. 72, no. 1, pp. 24-30, 2010.

[41] A. Kumar, A. G. C. Nair, A. V. R. Reddy, and A. N. Garg, "Bhasmas: unique Ayurvedic metallic-herbal preparations, chemical characterization," Biological Trace Element Research, vol. 109, no. 3, pp. 231-254, 2006.
[42] P. M. Tate, B. J. Prajapati, and P. K. Patgiri, "Pharmaceutical standardization of Naga bhasma," AYU, vol. 30, no. 3, pp. 300309, 2009.

[43] S. Kumar and P. S. Byadgi, "Critical appraisal of Madhumeha (Diabetes Mellitus)," International Journal of Research in Ayurveda and Pharmacy, vol. 2, no. 3, pp. 687-693, 2011.

[44] A. K. Tiwari, "Wisdom of Ayurveda in perceiving diabetes: enigma of therapeutic recognition," Current Science, vol. 88, no. 7, pp. 1043-1051, 2005.

[45] N. Dubey, R. S. Mehta, A. K. Saluja, and D. K. Jain, "Physicochemical and pharmacological assessment of a traditional biomedicine: mukta shouktic bhasma," Songklanakarin Journal of Science and Technology, vol. 31, no. 5, pp. 501-510, 2009.

[46] V. A. Dole and P. Paranjpe, A Textbook of Rasashastra, Chaukhambha Sanskrit Pratishthan, New Delhi, India, 2004.

[47] N. Kumar, A. Kumar, and M. L. Sharma, "Clinical evaluation of single and herbo-mineral compound drugs in the management of Madhumeha," Journal of Research in Ayurveda and Siddha, vol. 20, no. 1-2, pp. 1-9, 1999.

[48] C. E. Lagad and R. Ingole, "Pharmaceutical and clinical evaluation on Vanga bhasma in the management of Madhumeha (diabetes mellitus)," AYU, vol. 30, no. 4, pp. 443-446, 2009.

[49] S. Bhojashettar, B. T. Poornima, and P. G. Jadar, "Evaluation of market samples of "Yashada bhasma" using 'Namburi phased spot test," Journal of Ayurveda and Integrative Medicine, vol. 2, no. 2, pp. 69-71, 2011.

[50] H. S. Datta, S. K. Mitra, and B. Patwardhan, "Wound healing activity of topical application forms based on ayurveda," Evidence-Based Complementary and Alternative Medicine, vol. 2011, Article ID 134378, 10 pages, 2011.

[51] R. P. Tupe and S. A. Chiplonkar, "Zinc supplementation improved cognitive performance and taste acuity in Indian adolescent girls," The Journal of the American College of Nutrition, vol. 28, no. 4, pp. 388-396, 2009.

[52] T. K. Bhowmick, A. K. Suresh, S. G. Kane, A. C. Joshi, and J. R. Bellare, "Indian traditional medicine Jasada Bhasma and other zinc-containing nanoparticles alleviate reactive oxygen species-mediated cell damage in saccharomyces cerevisiae," International Journal of Green Nanotechnology: Biomedicine, vol. 1, no. 1, pp. B69-B89, 2009.

[53] R. V. Sathe, N. G. Talwalkar, and S. S. Ajgaonkar, "Treatment of diabetes with an oral Ayurvedic preparation-Jasada bhasma," Journal of the Association of Physicians of India, vol. 8, no. 4, pp. 331-333, 1960.

[54] C. M. Prasad and A. V. Sharma, "Yashada bhasma: an effective hypoglycemic drug," Ancient Science of Life, vol. 9, no. 2, pp. 6970, 1989.

[55] V. N. Rao, P. Suresh, S. K. Dixit, and K. D. Gode, "Effect of Yashada bhasma in streptozotocin induced diabetes," Ancient Science of Life, vol. 17, no. 2, pp. 1-3, 1997.

[56] S. Pandit, T. K. Biswas, P. K. Debnath et al., "Chemical and pharmacological evaluation of different ayurvedic preparations of iron," Journal of Ethnopharmacology, vol. 65, no. 2, pp. 149$156,1999$.

[57] N. Pattanaik, A. V. Singh, R. S. Pandey et al., "Toxicology and free radicals scavenging property of Tamra bhasma," Indian Journal of Clinical Biochemistry, vol. 18, no. 2, pp. 181-189, 2003.

[58] C. Y. Jagtap, B. K. Ashok, B. J. Patgiri, P. K. Prajapati, and B. Ravishankar, "Comparative anti-hyperlipidemic activity of Tamra bhasma (incinerated copper) prepared from Shodhita (purified) and Ashodhita tamra (raw copper)," Indian Journal of Natural Products and Resources, vol. 4, no. 2, pp. 205-211, 2013. 
[59] Z. A. Shah and S. B. Vohora, "Antioxidant/restorative effects of calcined gold preparations used in Indian systems of medicine against global and focal models of ischaemia," Pharmacology \& Toxicology, vol. 90, no. 5, pp. 254-259, 2002.

[60] H. S. Shubha and R. S. Hiremath, "Evaluation of antimicrobial activity of Rasaka bhasma," AYU, vol. 31, no. 2, pp. 260-262, 2010.

[61] N. A. A. John and P. Brindha, "Effect of Yasada bhasma on oral sodium phosphate induced nephrocalcinosis in rats," International Research Journal of Pharmacy, vol. 2, no. 1, pp. 202-209, 2011.

[62] P. N. Reddy, M. Lakshmana, and U. V. Udupa, "Effect of Praval bhasma (Coral calx), a natural source of rich calcium on bone mineralization in rats," Pharmacological Research, vol. 48, no. 6, pp. 593-599, 2003.

[63] C. L. Brown, G. Bushell, M. W. Whitehouse et al., "Nanogoldpharmaceutics: (i) The use of colloidal gold to treat experimentally-induced arthritis in rat models; (ii) Characterization of the gold in Swarna bhasma, a microparticulate used in traditional Indian medicine," Gold Bulletin, vol. 40, no. 3, pp. 245-250, 2007.

[64] T. K. Bhowmick, A. K. Suresh, S. G. Kane, A. C. Joshi, and J. R. Bellare, "Physicochemical characterization of an Indian traditional medicine, Jasada Bhasma: detection of nanoparticles containing non-stoichiometric zinc oxide," Journal of Nanoparticle Research, vol. 11, no. 3, pp. 655-664, 2009.

[65] S. Nagarajan, B. Pemiah, U. M. Krishnan, K. S. Rajan, S. Krishnaswamy, and S. Sethuraman, "Physico-chemical characterization of lead based Indian traditional medicine-Naga bhasma," International Journal of Pharmacy and Pharmaceutical Sciences, vol. 4, no. 2, pp. 69-74, 2012.

[66] C. E. Lagad, R. S. Sawant, and P. Yelambkar, "An approach towards standardization of Swarna Makshik bhasma (an Ayurvedic preparation)," International Journal of Research in Ayurveda and Pharmacy, vol. 2, no. 3, pp. 723-729, 2011.

[67] S. Mohapatra and C. B. Jha, "Physicochemical characterization of Ayurvedic bhasma (Swarna Makshika bhasma): an approach to standardization," International Journal of Ayurveda Research, vol. 1, no. 2, pp. 82-86, 2010.

[68] N. Singh and K. R. C. Reddy, "Particle size estimation and elemental analysis of Lauha bhasma," International Journal of Research in Ayurveda and Pharmacy, vol. 2, no. 1, pp. 30-35, 2011.

[69] B. Krishnamachary, N. Rajendran, B. Pemiah et al., "Scientific validation of the different purification steps involved in the preparation of an Indian Ayurvedic medicine, Lauha bhasma," Journal of Ethnopharmacology, vol. 142, no. 1, pp. 98-104, 2012.

[70] K. Ishihara, K. Yamanami, M. Takano et al., "Zinc bioavailability is improved by the micronised dispersion of zinc oxide with the addition of L-histidine in zinc-deficient rats," Journal of Nutritional Science and Vitaminology, vol. 54, no. 1, pp. 54-60, 2008.

[71] F. M. Hilty, M. Arnold, M. Hilbe et al., "Iron from nanocompounds containing iron and zinc is highly bioavailable in rats without tissue accumulation," Nature Nanotechnology, vol. 5, no. 5, pp. 374-380, 2010

[72] R. D. Umrani, D. S. Agrawal, and K. M. Paknikar, "Anti-diabetic activity and safety assessment of Ayurvedic medicine, Jasada bhasma (zinc ash) in rats," Indian Journal of Experimental Biology, vol. 51, no. 10, pp. 811-822, 2013.

[73] R. D. Umrani and K. M. Paknikar, "Ayurvedic medicine zinc bhasma: physicochemical evaluation, anti-diabetic activity and safety assessment," Journal of Biomedical Nanotechnology, vol. 7, no. 1, pp. 148-149, 2011.

[74] R. D. Umrani, Studies on anti-diabetic activity of zinc based submicronic preparations [Ph.D. thesis], University of Pune, Pune, India, 2011.

[75] R. D. Umrani and K. M. Paknikar, "Zinc oxide nanoparticles show antidiabetic activity in streptozotocin-induced Type 1 and 2 diabetic rats," Nanomedicine, vol. 9, no. 1, pp. 89-104, 2014.

[76] S. M. Moghimi, A. C. Hunter, and J. C. Murray, "Nanomedicine: current status and future prospects," FASEB Journal, vol. 19, no. 3, pp. 311-330, 2005.

[77] T. Xia, M. Kovochich, M. Liong et al., "Comparison of the mechanism of toxicity of zinc oxide and cerium oxide nanoparticles based on dissolution and oxidative stress properties," ACS Nano, vol. 2, no. 10, pp. 2121-2134, 2008.

[78] V. Dwivedi, B. K. Tripathi, M. Mutsuddi, and S. C. Lakhotia, "Ayurvedic amalaki rasayana and rasa-Sindoor suppress neurodegeneration in fly models of Huntington's and Alzheimer's diseases," Current Science, vol. 105, no. 12, pp. 1711-1723, 2013. 


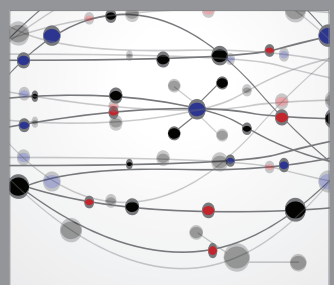

The Scientific World Journal
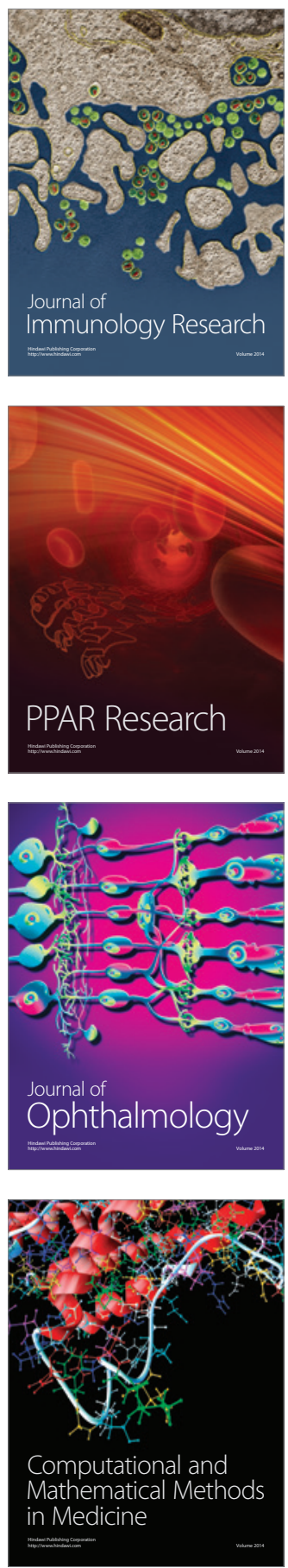

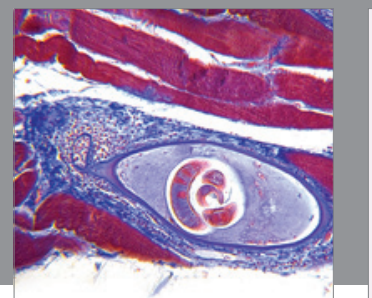

Gastroenterology

Research and Practice
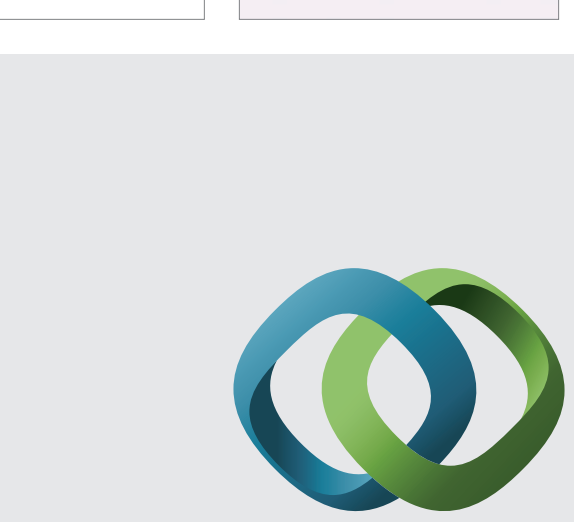

\section{Hindawi}

Submit your manuscripts at

http://www.hindawi.com
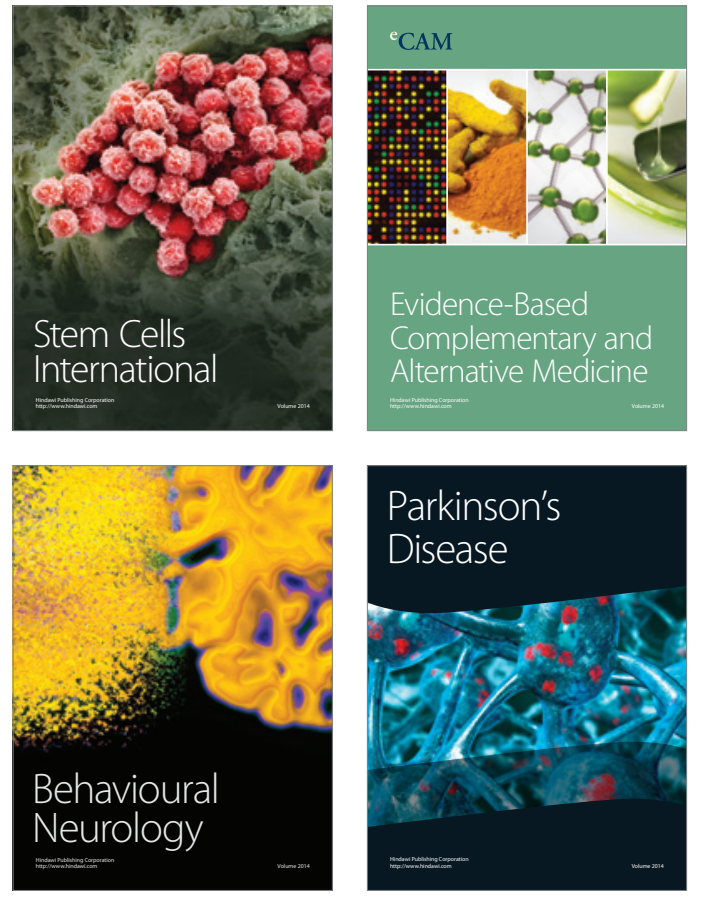
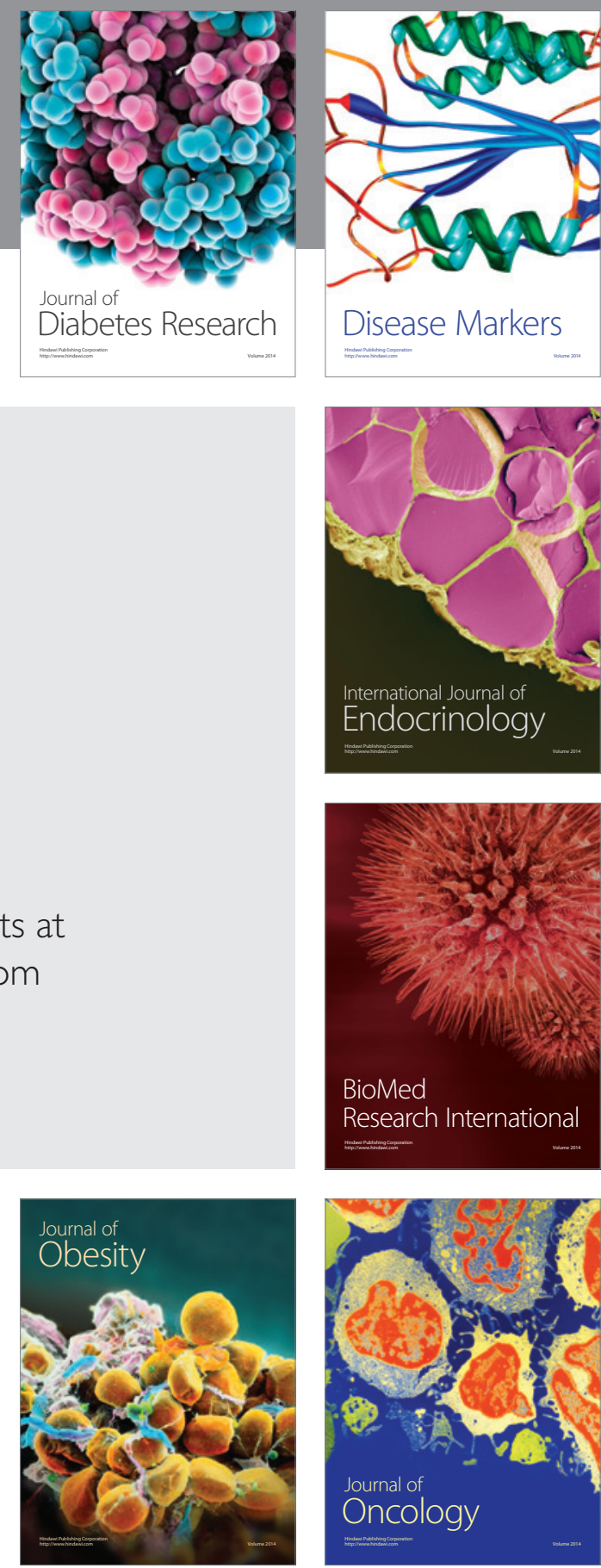

Disease Markers
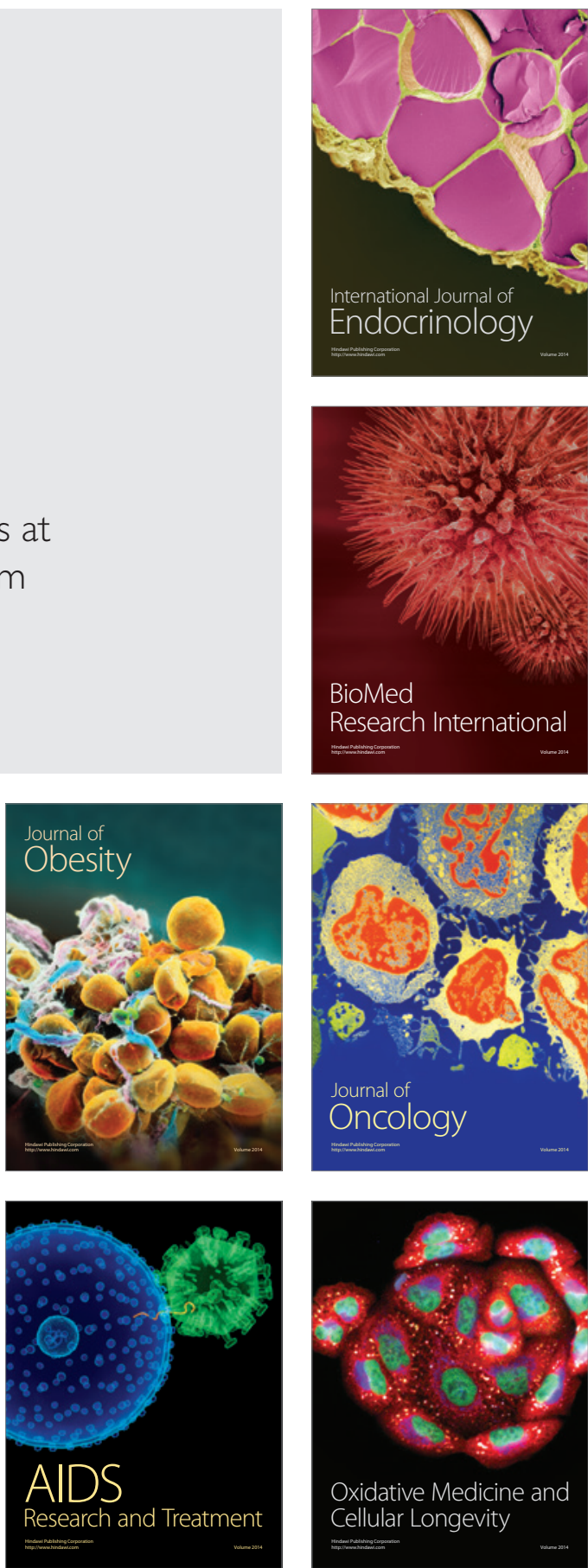